\title{
A case of late diagnosis of duodenal stenosis in an adolescent with Down syndrome
}

\author{
Alessandra Loiodice ${ }^{1 *}$, Lucia Montenegro ${ }^{1}$, Mariangela Loiacono ${ }^{1}$, Isabella Franco ${ }^{1}$ and Ippazio Ugenti $^{1,2}$ \\ ${ }^{1}$ Departement Unit of Digestive Endoscopy, I.R.C.C.S. Istituto Tumori “Giovanni Palo II", Bari, Italy \\ ${ }^{2}$ D.E.T.O, University of Bari “A. Moro”, Italy
}

\section{Introduction}

Down syndrome (DS) is the most common chromosomal disorder associated with various organ malformations. Among these, gastrointestinal malformations are described in 4 to $10 \%$ of patients. The most common are duodenal atresia or stenosis, annular pancreas, imperforate anus, esophageal atresia, congenital megacolon $[1,2]$. Usually, the duodenal stenosis or atresia symptoms and signs onset early, during prenatal or neonatal period. The most of case reports reported in literature regards infants and nurslings. Few cases of late diagnosis of duodenal stenosis are described. Perhaps because of mental retardation some symptoms as vomiting could be underestimated [3-6]

\section{Case Report}

We report the case of a 16-years-old boy with Down syndrome, outpatient, came to our attention because of dyspepsia and epigastric pain. He underwent esophagogastroduodenoscopy. The exam showed mild esophagitis, a few residual food in the stomach and normal pyloric sphincter. The duodenal bulb was considerably dilated, at least triple respect normal (it was possible to perform the retroversion maneuver inside it). The passage to the second portion of duodenum was impossible, even with the $6 \mathrm{~mm}$ gastroscope, because of the presence of an annular narrowing (Figure 1 and 2). So, the patient was referred to surgery.

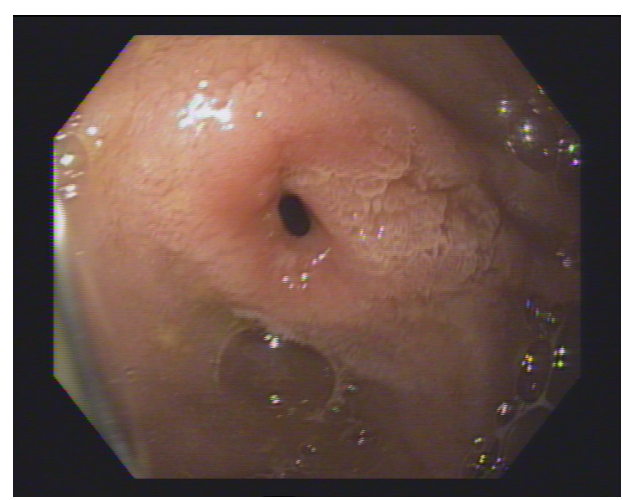

Figure 1. Stenosis of the duodenal apex

Copyright: (C2021 Loiodice A. This is an open-access article distributed under the terms of the Creative Commons Attribution License, which permits unrestricted use, distribution, and reproduction in any medium, provided the original author and source are credited.
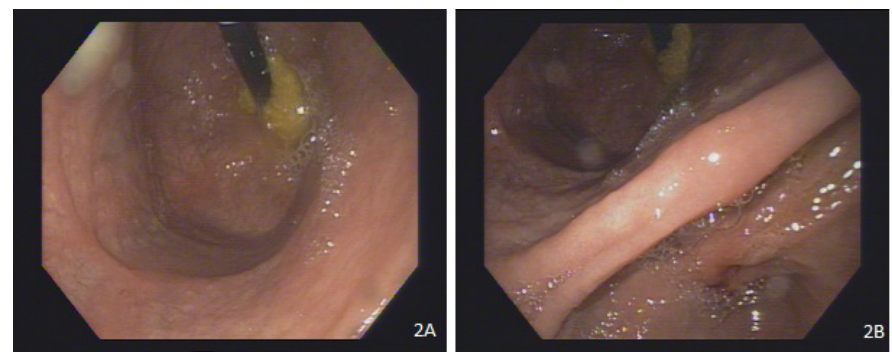

Figure 2. Dilation of duodenal bulb and retroversion maneuver inside it

\section{Conclusion}

In conclusion, it could be useful remember that gastrointestinal malformations are common in Down syndrome and they would be considered in cases of gastrointestinal disturbances, even when the symptoms are mild, and the patient has passed the childhood age.

\section{References}

1. Bermudez BEBV, de Oliveira CM, de Lima Cat MN, Magdalena NIR, Celli A (2019) gastrointestinal disorders in down syndrome. Am J Med Genet 179: 1426-1431. [Crossref]

2. Cleves MA, Hobbs CA, Cleves PA, Tilford JM, Bird TM, et al. (2007) Congenital Defects among Liveborn Infants with Down Syndrome. Birth Defects Res A Clin Mol Teratol 79: 657-663. [Crossref]

3. Savino A, Rollo V, Chiarelli F (2007) Congenital duodenal stenosis and annular pancreas: a delayed diagnosis in an adolescent patient with Down syndrome. Eur $J$ Pediatr 166: 379-380. [Crossref]

4. Nicholson MR, Acra SA, Chung DH, Rosen MJ (2014) Endoscopic Diagnosis of Duodenal Stenosis in a 5-Month-Old Male Infant. Clin Endosc 47: 568-570. [Crossref]

5. Sachs BF, Feldman W (1973) Upper Gastrointestinal Bleeding Associated with Congenital Duodenal Stenosis and Down's Syndrome. Clin Pediatr 12: 21. [Crossref]

6. Smith GV, Teele RL (1980) Delayed Diagnosis of Duodenal Obstruction in Down Syndrome. AJR Am J Roentgenol 134: 937-940. [Crossref]
*Correspondence to: Alessandra Loiodice, viale Orazio Flacco 65, 70124 Bari, Italy, Tel: +393497924283; E-mail: a.loiodice@oncologico.bari.it

Received: March 08, 2021; Accepted: March 19, 2021; Published: March 22, 2021 